\title{
Energy Storage Selection for LEO Satellites
}

\author{
B. Abdi, A. Alimardani, R. Ghasemi, and S. M. M. Mirtalaei, Member, IACSIT
}

\begin{abstract}
This paper presents two energy storage systems, based on chemical batteries and flywheels as the energy source of low earth orbit satellites in eclipse duration. Each system is designed and optimized with regard to energy requirement of a typical LEO satellite and various vital parameters in satellites which are discussed. The storage system and electronic interface are presented to give an adequate view for comparing them in different aspects. Afterwards, a comparison between these energy storage systems (ESSs) is applied considering their efficiency, reliability, weight, operational temperature and self-discharge dissipation (trickle charge). Finally, the conclusion presents the most recommended system in order of their capability.
\end{abstract}

Index Terms-Energy storage system, chemical battery, flywheel, LEO Satellite.

\section{INTRODUCTION}

Energy management has always been an important issue in satellite applications. Satellites can be categorized to Geostationary Orbit (GEO), Low Earth Orbit (LEO) and Medium Earth Orbit (MEO) satellites [1]. LEO satellites take place at 300 to 1000 kilometers orbits from the earth [1], [2]. Due to short distance from the sun, LEO satellites require low power. Therefore, usually their entire energy is supplied from sun light. On the other hand, most of these satellites spend a part of their rotational period in eclipse. So, an energy storage system (ESS) is inevitable to keep them alive in eclipse duration.

The discussed satellite in this paper is a typical micro satellite with a distance of a typical LEO satellite from the earth is about $700 \mathrm{~km}$. So, the period duration is about 90 minutes, including 30 minutes of eclipse and 60 minutes at sun light. It has $40 \mathrm{~W}$ average power consumption and the voltage of DC bus is 28 volts. When the satellite is open at sun light (charging state), the ESS should be charged and save adequate energy to supply the satellite's required power in eclipse duration (discharge state).

In a general view, the most commonly technologies for short term energy storage are chemical Batteries energy storage systems (CBESS), Flywheel Energy Storage Systems (FESS) and Superconducting magnetic energy storage system (SMESS) [3], [4]. The most important parameters in an ESS for satellites applications are efficiency, lifetime, reliability, operative temperature, weight, volume and cost of system.

Energy storage systems of LEO satellites were only chemical batteries until the late of 90th decade which NASA employed flywheel energy storage systems in international

Manuscript received January 23, 2013; revised May 18, 2013.

This work was supported in part by Damavand Branch, Islamic Azad University.

The Authors are with Damavand Branch, Islamic Azad University, Damavand, Tehran, Iran (e-mail: babakabdi@ieee.org). space station [5], [6]. The most important problem with batteries is the limitation of their charge and discharge cycles which shorten their lifetime and performance [7]. LEO satellites have a period of 1.5 to 1.74 hours respective to their orbit, so the rate of charge/discharge is very high and this reduces batteries lifetime down to 3-5 years [7].

In 1976, Dr. Kirk from Maryland University and NASA proposed an investigation on application of flywheels as energy storage systems in satellites [8], [9]. They are rather to be built with high radius and work in high speed to store more energy instead of having high weight. So, beside chemical batteries, Flywheels are comparative choices for such applications.

In this paper, two ESSs base on chemical batteries and flywheels are designed and optimized for LEO satellite applications as the source of energy when the satellite is in eclipse and the sun light is not accessible. Then, a comparison between these types of ESS is performed in different aspects including efficiency, reliability, weight, operational temperature and self-discharge dissipation (trickle charge) to choose the best ESS in this application.

The rest of this paper is organized as follows: In Section II, a chemical battery base energy storage system is designed. In Section III, a flywheel energy storage system is designed and optimized. Then, in Section IV, a comparison between these energy storage systems considering regard to their efficiency, reliability, operational temperature, weight and self-discharging dissipation is presented. Finally, conclusion depicts which energy storage system is the most optimum one in different approaches.

\section{Chemical BATtery BASE ENERGy StORAGE SyStem}

Since Chemical batteries are the most common ESSs, the first discussed ESS is based on chemical batteries. Recently, Chemical batteries technology had many improvements in different applications. This type of energy storage system is very accessible and comes with low price rather than many other storage systems. Moreover, batteries are static devices and this is an advantage in comparison with than dynamic storage units such as flywheels.

\section{A. Battery Arrangement}

Two common types of batteries which are used in space programs are Ni-Cd and Ni-H2. Table I depicts the properties of these batteries.

TABLE I: PROPERTIES OF NI-CD AND NI-H2 BATTERIES [10]

\begin{tabular}{lll}
\hline \hline Battery Properties & Ni-Cd & Ni-H2 \\
\hline Specific energy $(\mathrm{Wh} / \mathrm{kg})$ & 30 & 60 \\
Energy efficiency $(\%)$ & 72 & 70 \\
Self discharge $(\% /$ day $)$ & 0.5 & 5 \\
Temperature range $\left({ }^{\circ} \mathrm{C}\right)$ & 0 to 40 & -20 to 30 \\
Cell voltage $(\mathrm{V})$ & 1.2 & 1.2 \\
Memory effect & Yes & Yes \\
\hline \hline
\end{tabular}


Cd which results in lower weight. Although the self discharge rate of $\mathrm{Ni}-\mathrm{H} 2$ is more than $\mathrm{Ni}-\mathrm{Cd}$, but in $\mathrm{LEO}$ satellites, charge and discharge duration is very short, so the effect of this parameter is negligible. Also, operational temperature range of $\mathrm{Ni}-\mathrm{H} 2$ is more than $\mathrm{Ni}-\mathrm{Cd}$. Therefore, $\mathrm{Ni}-\mathrm{H} 2$ is more suitable for CBESS in this application.

The sample satellite's energy consumption is $40 \mathrm{~W}$ for 30 minutes (20Wh) in eclipse duration, and the maximum permitted depth of discharge for chemical batteries in low earth orbits is $15 \%$ [11]. So, the energy capacitor of batteries must be as follows:

$$
\frac{20 \mathrm{Wh}}{0.15}=133.33 \mathrm{Wh}
$$

According to available energy of each battery cell and considering DOD and voltage of DC bus, 22 cells in series are adequate. Table II indicates the result of battery design.

To calculate self-discharge dissipation, first the percent of discharge per second is determined. Then regard to average energy of batteries, the amount of dissipation energy per second is calculated which is equal to self-discharge power dissipation.

It should be clarified that the weight of BESS contains the weight of batteries and the whole package of it. So, the total weight is more than the weight of batteries alone $(22 \times 230 \mathrm{gr})$.

TABLE II: RESULT OF BATTERY DESIGN

\begin{tabular}{ccccc}
\hline \hline $\begin{array}{c}\text { Battery } \\
\text { Type }\end{array}$ & $\begin{array}{c}\text { Number } \\
\text { of Cells }\end{array}$ & $\begin{array}{c}\text { Weight } \\
\text { include } \\
\text { Box (kg) }\end{array}$ & $\begin{array}{c}\text { energy } \\
\text { efficiency }\end{array}$ & $\begin{array}{c}\text { Self-Discharge } \\
\text { Dissipation (W) }\end{array}$ \\
\hline $\begin{array}{c}\text { Memory } \\
\text { effect }\end{array}$ & 22 & 7.8 & $70 \%$ & 0.27 \\
\hline \hline
\end{tabular}

\section{B. Power Electronics of CBESS}

Generally, energy storage systems are connected to load through series and parallel structures. The parallel structure has more total efficiency [12]. Furthermore, different topologies are employed as DC-DC converter in energy conversion system of satellites. Each topology has its own advantages and disadvantages [13]. Bidirectional boost-buck topology is the most suggested topology in previous studies

The efficiency of CBESS power electronics based on this topology is about $95 \%$.

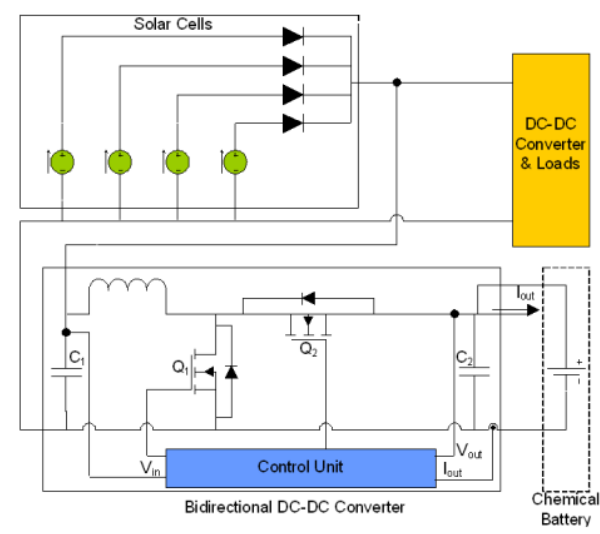

Fig. 1. Bidirectional boost-buck converter with parallel connection for a CBESS for satellite applications.

Fig. 1 illustrates the parallel structure of a bidirectional boost-buck DC-DC converter for a CBESS. As one can see, batteries are connected to the DC bus with a bidirectional DC-DC converter in parallel structure.

The control algorithm of this converter consists of three parts:

- When the satellite is receiving sun light, it should control the DC bus voltage regard to Maximum Power Point Tracking (MPPT) operation state of solar panels. Also, the batteries should be charged according to temperature and charge characteristics of batteries.

- When the batteries are charged, it just provides the trickle charge and standby for discharge state.

- Discharge the batteries to provide the satellite required energy in eclipse duration.

This control system handles the energy management of satellite in sun light duration as well as eclipse.

\section{FLYWHEEL BASE ENERGY STORAGE SySTEM}

In FESS, when the satellite is at sun light, the surplus of provided energy by solar cells is stored into rotational kinetic energy using an electrical machine. In eclipse duration, stored kinetic energy is converted into electrical energy.

The advantages of FESSs for satellite applications are presented in [8], [9], [14], and [15]. Unlimited charge/discharge cycle as well as the satellite lifetime, higher efficiency, higher energy density, higher discharge depths, thermal independency and their usage in attitude control of satellites can be mentioned as some of these advantages. Instruction for design and optimization of flywheel energy storage systems to achieve lower stress and weight for space applications are presented in [16], [17].

\section{Flywheel and Electrical Machine Design}

Two major parts of FESS are a flywheel and an electrical machine coupled together. Fig. 2 shows various parts of a typical FESS.

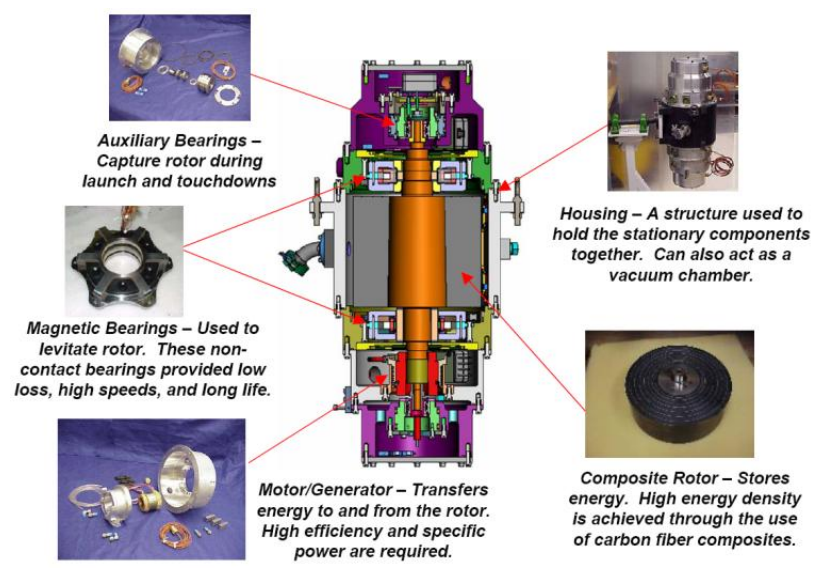

Fig. 2. Different components of a FESS [1].

The rotational speed of flywheels varies from 20000 to $60000 \mathrm{rpm}$ [15], [17]. In charge state, the machine works as a motor to convert the electrical energy into mechanical form and in discharge state, it works as a generator to return the energy in electrical form. This machine is usually a three phase one. So, it needs a three phase, variable speed, inverter. Table III depicts the result of design and optimization of a FESS for the discussed satellite [17]. 


\section{B. Power Electronics of FESS}

Fig. 3 illustrates the power electronic block diagram of FESS energy management. This circuit has an important difference with CBESS power electronic circuit. FESS power electronic circuit has an additional inverter to handle the electrical three phase machine. This inverter should be able to generate a variable frequency field proportional with the speed of flywheel [9].

TABLE III: RESULT OF FESS DESIGN AND OPTIMIZATION

\begin{tabular}{ccccc}
\hline \hline $\begin{array}{c}\text { Charge/ } \\
\text { discharge } \\
\text { Time }(\mathbf{s})\end{array}$ & $\begin{array}{c}\text { Min. } \\
\text { Speed } \\
(\mathbf{r p m})\end{array}$ & $\begin{array}{c}\text { Max. } \\
\text { Speed } \\
(\mathbf{r p m})\end{array}$ & $\begin{array}{c}\text { Min. line } \\
\text { voltage } \\
(\mathbf{V})\end{array}$ & $\begin{array}{c}\text { Max. line } \\
\text { voltage } \\
(\mathbf{V})\end{array}$ \\
\hline $3600 / 1800$ & 20000 & 60000 & 24 & 72 \\
\hline \hline $\begin{array}{c}\text { Energy } \\
\text { Efficiency }\end{array}$ & $\begin{array}{c}\text { Mass } \\
(\mathbf{k g})\end{array}$ & $\begin{array}{c}\text { Volume } \\
\left(\mathbf{c m}^{\mathbf{3}}\right)\end{array}$ & $\begin{array}{c}\text { Average self-discharge } \\
\text { (Iron losses) }(\mathbf{W})\end{array}$ \\
\hline $97 \%$ & 1.2 & 832 & & 0.8 \\
\hline \hline
\end{tabular}

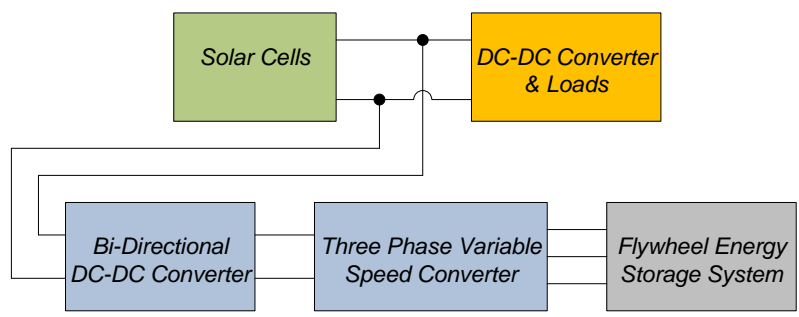

Fig. 3. Power electronic block diagram of FESS.

The efficiency of this additional inverter is maximum $95 \%$. So, the total efficiency of FESS power electronic is $90.25 \%$.

The control algorithm of FESS for charge and discharge is similar to CBESS.

\section{COMPARISON}

In this section, an integral comparison among these ESSs is discussed in order of importance. The comparison is classified in five branches including efficiency, reliability, operational temperature, weight and self-discharge dissipation.

\section{A. Efficiency}

Efficiency is the most important parameter in satellite applications; because a higher efficiency system results in less solar panel area and less thermal problems. So, this aspect is considered as the first comparison topic.

According to Tables II and III, the efficiency of flywheels is about $27 \%$ more than chemical batteries. FWESS has an additional 3phase power inverter with maximum efficiency of $95 \%$. Due to equal efficiency in charge and discharge state of FWESS, total energy efficiency of this ESS is $76.63 \%$ $\left([95 \% \times 95 \% \times 97 \%]^{2}\right)$. The energy efficiency of batteries is $70 \%$, so the total efficiency of CBESS is $63.17 \%$ $\left([70 \% \times 95 \%]^{2}\right)$. Therefore, FWESS is the most suitable choice, in this point of view.

\section{B. Reliability}

Since there are no access possibilities to repair LEO satellites in the space, Mead Time Between Failure (MTBF) is equal to satellite lifetime. So, reliability is the second most important parameter in design of a satellite.

According to MIL-HDBK-217, less employed components and less losses and temperature result in more reliability [18]. Due to additional inverter in FESS which means more losses and higher temperature, beside more employed components, FWESS drive circuits has the least reliability among these ESSs drive circuits.

On the other hand, Chemical batteries have short lifespan rather than flywheels, which mean low reliability.

Flywheels deal with high mechanical stresses because of their high rotational speed. Flywheels work in very high speeds and suffer many of mechanical stresses. So, due to these mechanical stresses and their drive circuit, they have lower reliability than chemical batteries. As a summery, CBESS is the most reliable ESS.

\section{G. Operational Temperature}

As the satellite spins around the earth, its distance from the sun is rapidly variable as well as its temperature. According to Table I, the chosen chemical battery has a limited operational temperature range between $-20^{\circ} \mathrm{C}$ to $30^{\circ} \mathrm{C}$ [10]. In FESSs, temperature variations affect the permanent magnets used in electrical machine for $2.5 \%$ error rate in every $10^{\circ} \mathrm{C}$ [17]. So, in this approach FWESS is the most flexible option and CBESS has the second rank.

\section{H. Weight}

Expensive launch of satellites is proportional to their weight. So, weight is an important parameter in design. According to Tables II and III and the result of optimum design procedure, CBESS is $6.6 \mathrm{~kg}$ heavier than FWESS. So, FWESSs are excellent in this point of view.

\section{Self-discharge Dissipation (Trickle Charge)}

Every ESS has an internal dissipation. So, a very low current is necessary to fix them in fully charge state (Trickle charge). According to Tables II and III, FWESS has $0.53 \mathrm{~W}$ self-discharge dissipation more than CBESS. Therefore FWESS need more trickle charge in comparison with CBESSs.

\section{CONCLUSION}

In this paper, the main properties of a typical LEO satellite are presented. Different energy storage systems for energy supplements are discussed, designed and optimized. Then, a comparative approach within them is done respect to efficiency, reliability, operational temperature, weight, self-discharge dissipation to find the best choice for energy storage system in satellite applications. Considering the advantages and disadvantages of each ESS altogether, Flywheel base ESS is the most recommended ESS due to higher efficiency, reliability, operational temperature range.

\section{REFERENCES}

[1] NASA Langley Reasearch Center. [Online]. Available: http://www.larc.nasa.gov

[2] The Tech Museum of Innovation. [Online]. Available: http://www.thetech.org

[3] C. S. Wang and M. H. Nehrir, "Power management of a stand-alone wind/Photovoltaic/Fuel cell energy system," IEEE Trans. on Energy Conversion, vol. 23, no. 3, pp. 957-967. Sep. 2008

[4] C. Abbey and G. Joos, "Supercapacitor energy storage for wind energy applications," IEEE Trans. on Industry Applications, vol. 43, no. 3, pp 769-776, May-June 2007.

[5] D. Christopher, R. F. Beach, and J. R. Barton, "A flywheel energy storage system test on the International Space Station," NASA Lewis Research Center, 1996. 
[6] P. E. Kascak, B. H. Kenny, T. P. Dever, W. Santiago, and R. H. Jansen, "International space station bus regulation with NASA glenn research center flywheel energy storage system development unit," IECEC, 29 Jul., 2001.

[7] E. Lee, "A micro HTS renewable energy/attitude control system for micro/nano satellites," IEEE Trans. on Applied Superconductivity, vol. 13, no. 2, June 2003.

[8] J. A. Kirk and P. A. Studer, "Mechanical Capacitor," NASA TND-8185, 1976.

[9] G. E. Rodriguez, P. A. Studer, and D. A. Baer, "Assessment of flywheel energy storage for spacecraft power systems," NASA Technical Memorandum, May 1983.

[10] Saftabatteris. [Online]. Available: http://www.saftbatteris.com

[11] C. D. Brown, "Elements of spacecraft design," AIAA Education Series, Parallel Structure, 2002.

[12] R. Gules, J. P. Pacheco, H. L. Hey, and J. Imhoff, “A maximum power point tracking system with parallel connection for PV stand-alone applications," IEEE Trans. on Industrial Electronics, vol. 55, no. 7, July 2008.

[13] W. Xiao, N. Ozog, and W. G. Dunford, "Topology study of photovoltaic interface for maximum power point tracking," IEEE Trans. on Industrial Electronics, vol. 54, no. 3, June 2007.

[14] M. A. Arslan, "Flywheel geometry design for improved energy storage using finite element analysis," ELSEVIER Trans. on Material and Design, 2007.

[15] W. Wang, "Design of high speed flywheel motor/generator for aerospace applications," Ph.D. dissertation, The Pennsylvania State University, 2003.

[16] M. A. Arslan, "Flywheel geometry design for improved energy storage using finite element analysis," ELSEVIER Trans. on Material and Design, 2007.

[17] B. Abdi, J. Milimonfared, J. S. Moghani, and A. K. Kaviani, "Simplified design and optimization of slotless halbach machine for micro-satellite's electro-mechanical batteries," International Review of Electrical Engineering (I.R.E.E.), vol. 4, no. 2, April 2009.

[18] "Reliability prediction of electronic equipments," Military handbook; MIL-HDBK-217F, Jan. 1992.

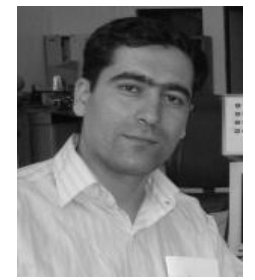

Babak Abdi Babak Abdi was born in Tehran in 1976. He received his M.S. and Ph.D. degree in electrical engineering in 2005 and 2009 from Amirkabir University of Technology (Tehran Polytechnic), Tehran, Iran, respectively. $\mathrm{He}$ is currently a member of IEEE and a faculty member of Damavand branch, Islamic Azad University, Tehran, Iran. His research interests include power electronics, application of reliability in power electronics, Electromagnetic Interferences (EMI), and electrical machines and drives.

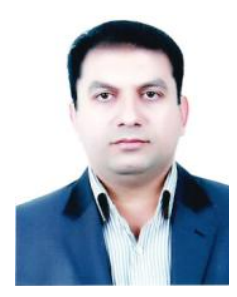

Reza Ghasemi was born in Tehran, Iran in 1979. He received his B.Sc. degree in Electrical engineering from Semnan University in 2000. He received the M.Sc. and the Ph.D. degree in control engineering from Amirkabir University of Technology, Tehran, Iran in 2004 and 2009, respectively. His research interests include large-Scale Systems, adaptive control, robust control, nonlinear control, and intelligent systems. Reza Ghasemi joined the Department of Electrical Engineering, Damavand Branch, Islamic Azad University, Tehran, Iran, where he is currently an assistant professor of electrical engineering.

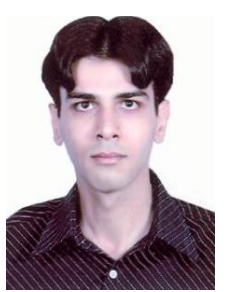

Sayyed Mohammad Mehdi Mirtalaei was born in Shahreza-Isfahan, Iran in 1983. He received his B.S. degree in electrical engineering from Isfan University of Technology, Iran in 2005. He received his M.S. and Ph.D. in electrical engineering from Amirkabir University of Technology, Tehran, Iran in 2007 and 2012 respectively. His research interest are power electronics, EMI/EMC and numerical method in electromagnetic. 